\title{
EMPLOYMENT OUTCOMES FOR PEOPLE WITH SCHIZOPHRENIA SPECTRUM DISORDER: A META-ANALYSIS OF RANDOMIZED CONTROLLED TRIALS
}

\author{
VIVIANA R. CARMONA ${ }^{1}$, JUANA GÓMEZ-BENITO ${ }^{1,2}$, TANIA B. HUEDO-MEDINA ${ }^{3}$, and J. EMILIO ROJO ${ }^{4,5}$ \\ ${ }^{1}$ University of Barcelona, Barcelona, Spain \\ Department of Behavioral Sciences Methods \\ ${ }^{2}$ University of Barcelona, Barcelona, Spain \\ Institute for Brain, Cognition and Behavior (IR3C) \\ ${ }^{3}$ University of Connecticut, Storrs, USA \\ Department of Allied Health Sciences \\ ${ }^{4}$ Hospital Benito Menni CASM, Sisters Hospitallers, Sant Boi de Llobregat, Spain \\ ${ }^{5}$ International University of Catalonia, Barcelona, Spain \\ Department of Psychiatry
}

\begin{abstract}
Access to employment plays a critical role in the recovery and functioning of people with schizophrenia. We have investigated the effectiveness of treatments to enhance employment outcomes for people with schizophrenia and evaluated the potential moderators of these outcomes. A literature search was conducted in CINAHL, Cochrane Databases, MEDLINE, ProQuest XML, PsycINFO, Scopus, and Web of Science. Grey literature databases, references lists of the retrieved articles and specialized journals in the field were also inspected. Job placement, job tenure and wages earned were tested. Risk ratios were extracted for job placement and standardized mean differences were calculated for job tenure and wages earned. Twenty-five randomized controlled trials published between 1986 and December 2015 were analyzed. Engaging in a vocational intervention increases the likelihood of obtaining a competitive job (risk ratio $(\mathrm{RR})=2.31$, $95 \%$ confidence interval (CI): 1.85-2.88) and has a positive impact on hours worked in any job (standardized mean difference $(\mathrm{SMD})=0.42,95 \%$ CI: 0.16-0.68). There was no evidence of intervention efficacy with regard to wages earned from competitive employment. Participation in rehabilitative vocational treatment is not sufficient to ensure work participation for people with schizophrenia. Comprehensive treatments are necessary to address functional deficits that hinder labor stability and job performance for people with schizophrenia. Int J Occup Med Environ Health 2017;30(3):345-366
\end{abstract}

Key words:

Vocational rehabilitation, Unemployment, Job placement, Job tenure, Supported employment, Wages earned

Funding: this work was supported by Spain's Ministry of Economy and Competitiveness (grant No. PSI2015-67984-R, grant manager: Juana Gómez-Benito, Ph.D.) and the Agency for the Management of University and Research Grants from the Government of Catalonia (grant No. 2014SGR1139, grant manager: Juana GómezBenito, Ph.D.).

Received: July 22, 2016. Accepted: January 2, 2017.

Corresponding author: J. Gómez-Benito, University of Barcelona, Department of Behavioral Sciences Methods, Faculty of Psychology, Passeig de la Vall d'Hebron 171, C.P. 08035 Barcelona, Spain (e-mail: juanagomez@ub.edu). 


\section{INTRODUCTION}

Though most people with psychiatric disabilities show a desire to work, they are more likely to experience adverse labor market outcomes than people without psychiatric disabilities [1]. In fact, the literature indicates that employment rates for people with schizophrenia are much lower than in the general population, ranging between $14.5-17.2 \%$ in the United States (USA) [2,3] and $11.5 \%$ in France, $12.9 \%$ in the United Kingdom (UK) and $30.3 \%$ in Germany [4], placing people with schizophrenia among those disability groups that are highly likely to be unemployed [5].

These findings mean that the schizophrenia has a considerable economic burden on families and health systems; they also suggest that people with schizophrenia do not enjoy the multiple benefits of paid employment, which are widely documented. Employment is known to increase self-esteem, foster a sense of belonging and physical well-being, and provide a normative context that helps people develop a sense of control over their lives [6-9]. On the basis of these benefits, current reviews focus on providing evidence of the supported employment model as an effective approach to improve employment outcomes, concluding that this model produces better competitive employment outcomes in people with severe mental illness than other vocational programs [10-13]. These reviews provide additional evidence for the efficacy of the supported employment approach; however, they focus on only one vocational approach and assess employment in a heterogeneous population of people with different diagnoses and specific characteristics. With the exception of two narrative reviews [14,15], and one meta-analysis [16], there is less evidence regarding the impact of a variety of interventions to enhance employment outcomes for people with schizophrenia.

Characteristics associated with schizophrenia, such as the high level of disability in multiple domains of daily functioning [17], the lesser likelihood of benefiting from employment programs for people with disabilities [5], and the specific employment patterns [16], call for a comprehensive approach to address unemployment, considering both the specific characteristics of the illness and the employment context in each case. Therefore, the aim of this report is to investigate the effectiveness of treatments to enhance employment outcomes for people with schizophrenia, based on an exhaustive search of the literature that focuses on randomized controlled trials and includes outcomes for competitive employment and any employment. We assessed the efficacy of these programs in terms of job placement and job tenure. As a secondary outcome, we assessed the wages earned from competitive employment. The efficacy of these treatments was tested against other vocational interventions provided by local vocational rehabilitation services. We also proposed to identify predictor variables that may influence employment outcomes based on sample and study characteristics.

\section{METHODS}

\section{Data collection}

For the meta-analysis we adhered to the Preferred Reporting Items for Systematic Reviews and Meta-Analyses (PRISMA) guidelines [18]. Three strategies were used for identifying studies for possible inclusion in our meta-analysis. Firstly, we conducted a literature search in the following electronic databases: CINAHL, Cochrane Databases, MEDLINE (via Pubmed), ProQuest XML, PsycINFO, Scopus, and Web of Science. Grey literature databases (Conference Papers Index and System for Information on Grey Literature in Europe (SIGLE)) were also used. Secondly, we identified potentially relevant studies through the references of the articles identified in the literature search. Thirdly, we manually inspected specialized journals in the field to identify studies that might have been published after the initial search was conducted. The following key terms were utilized in the search: schizophrenia, schizophrenic, schizoaffective, psychosis, psychotic, supported employment, individual placement and 
support, employment rehabilitation, psychosocial rehabilitation, psychiatric rehabilitation, occupational rehabilitation, work rehabilitation, job rehabilitation, sheltered work, transitional employment, rehabilitation counselling, vocational rehabilitation, randomized controlled trial, clinical trial. The search strategy in the PsycINFO database was as follows: ((schizophre* OR schizoa* OR psychosis OR psychotic) AND ((supported employ*) OR (individual placement) OR (employment rehab*) OR (psychosocial rehab*) OR (psychiatric rehab*) OR (occupational rehab*) OR (work rehab*) OR (job rehab*) OR (sheltered work*) OR (transitional employ*) OR (rehabilitation counselling) OR (vocational rehabilitation)) AND ((randomized controlled trial) OR (clinical trial)) in abstract. The search covered the period from 1900 to December 31, 2015, and studies from any country or reported in any language, although only reports in English were found.

\section{Inclusion criteria}

Trials were included in the meta-analysis if:

- they were randomized controlled trials that provided employment outcomes,

- the sample included at least $50 \%$ of individuals with schizophrenia spectrum disorder (schizophrenia, schizoaffective disorder and schizophreniform disorder),

- the study measured at least one primary outcome, job placement or job tenure.

Trials were excluded if:

- the samples included people with diagnoses of a first psychotic episode since one episode is not necessarily indicative of a full schizophrenia diagnosis, and this population corresponds to younger people with other needs associated with recent interruption of work and educational trajectories [19,20],

- the intervention duration was shorter than six months,

- no inference test was reported or insufficient descriptive information was provided (percentages or means and variability measures for both groups).

\section{Data extraction}

A coding manual and form were developed and pilot tested (available upon request to the corresponding author). Two coders were trained to extract information reliably. For each study we extracted statistical data for vocational treatment and control, and sample and study characteristics. The characteristics of participants included proportion of men, age, educational level, ethnicity, interest in getting a job, and diagnosis and other clinical characteristics, such as illness duration and illness onset. For study characteristics we included blinding, interventions, comparisons, treatment duration, sample size, and statistics reported. Finally, we included dimensions, such as study identifier, publication year and study location.

\section{Outcomes measures}

The primary employment outcomes for this study were job placement and job tenure. Job placement was defined as the number of people in employment and job tenure was defined as the number of hours or weeks that the person remained in employment (hereinafter, "hours worked" and "weeks worked"). Both competitive and any employment were considered for these primary outcomes. As a secondary outcome, we assessed the wages earned from competitive employment.

The data for competitive employment corresponded to outcomes derived from integrated paid work with at least minimum wage, and not reserved for people with disabilities [21]. The data for any employment corresponded to outcomes derived from any paid work, including sheltered workshops or transitional employment with wages. The outcomes from studies that gave data in combined form (for example: one rate of paid employment including both competitive employment and sheltered employment) were coded as any employment. When the study did not specify the nature of the employment outcome (competitive or any employment) we reviewed the coincidence between the concept defined in the trial and the definition 
of competitive employment [21]. When we could not establish which type of employment outcome was obtained, we used a conservative approach and coded the outcome as any job. A methodological quality scale adapted from Miller et al. [22] and Jadad et al. [23] was used for assessing the methodological quality of the included studies. This scale has 16 items and a response range of 0-22 points, with higher scores indicating greater methodological quality of the study. The inter-rater reliability was calculated: mean Cohen's [24] $\kappa=0.90$ for categorical variables and mean intra-class correlation $r=0.91$ for continuous variables. Disagreements were solved by discussion with a third expert.

\section{Data synthesis and analysis}

Different effect size indexes, with $95 \%$ confidence intervals (CI), were used depending on the continuous or dichotomous nature of the outcome. Risk ratios (RRs) were calculated for job placement, and standardized mean differences (SMDs) were calculated for job tenure and wages earned. The data used for generating RR was entered so that values above 1 indicated a greater likelihood of obtaining a job for the intervention group relative to the control group. The sign of the SMD for job tenure and competitive wages earned was positive for increases in hours or weeks worked and wages earned. The SMD was corrected for biases due to small sample sizes using the method of Hedges [25]. In cases of job tenure and wages earned, when mean and standard deviations were unavailable, SMDs were calculated from t-test values, F-tests or Z-tests.

For studies that compared three vocational approaches, using one intervention as a control condition [26,27], we followed the recommendations of the Cochrane Collaboration and divided the control group into two equal groups, so the total number of participants in both groups made up the size of the original sample. Heterogeneity was examined using the $\mathrm{Q}$ test [28] and the $\mathrm{I}^{2}$ index and its corre- sponding 95\% confidence intervals [28,29] were calculated to determine the variability of effect sizes. The $\mathrm{I}^{2}$ index describes the percentage of total variation across trials that are due to heterogeneity rather than sampling error, with values of $25 \%, 50 \%$ and $75 \%$ indicating low, moderate, and high heterogeneity, respectively [30]. We used a random-effects model when statistically significant heterogeneity was found and fixed-effects model - when no significant heterogeneity was observed in the effect sizes [31]. Forest plots were used for displaying the combined results. Publication bias was investigated using Begg's strategy [32] and Egger's test [33], with $p$-value $<0.05$ representing a significant bias. In the absence of publication bias, there is no relationship between effect sizes and variance, but if publication bias is present, a large variance should be associated with a large effect size because small studies with larger variances are more likely to be published if they show larger effect sizes [34].

Subgroup analyses were performed according to a) the nature of employment (competitive job or any employment) and b) types of vocational rehabilitation interventions (supported employment, including individual placement and support, and non-supported employment treatments). The sensitivity analysis was conducted to test the impact of the following studies on the overall effect size: the study with the largest sample size, the study with the largest effect size, studies in which treatment was augmented with other interventions, studies with two interventions and only one control group, and studies in which the employment outcome was a secondary goal. The meta-regression analysis was carried out to assess sources of heterogeneity and to identify the variables that may influence employment outcomes based on sample characteristics (age, educational level, gender, ethnicity, interest in getting a job and diagnosis) and study characteristics (sample size, treatment duration, blinding, publication year and methodological quality score). The analyses were performed with Metafor Package, v. 1.9-7 [35] in the statistical software R-Project package, version 3.1.2 [36]. 


\section{RESULTS}

\section{Literature search}

A list of 40 abstracts was retrieved from the databases and references lists. Out of these, 15 studies were excluded. The definitive analysis included 25 randomized controlled trials. The selection process is illustrated in the Figure 1.

\section{Study characteristics}

Studies were conducted in the United States (19 trials), China (2 trials), Canada (1 study), Sweden (1 trial) and the United Kingdom (1 study), and 1 study examined a sample drawn from various European countries. The mean duration of the studies was 16.08 months (range: 6-24;

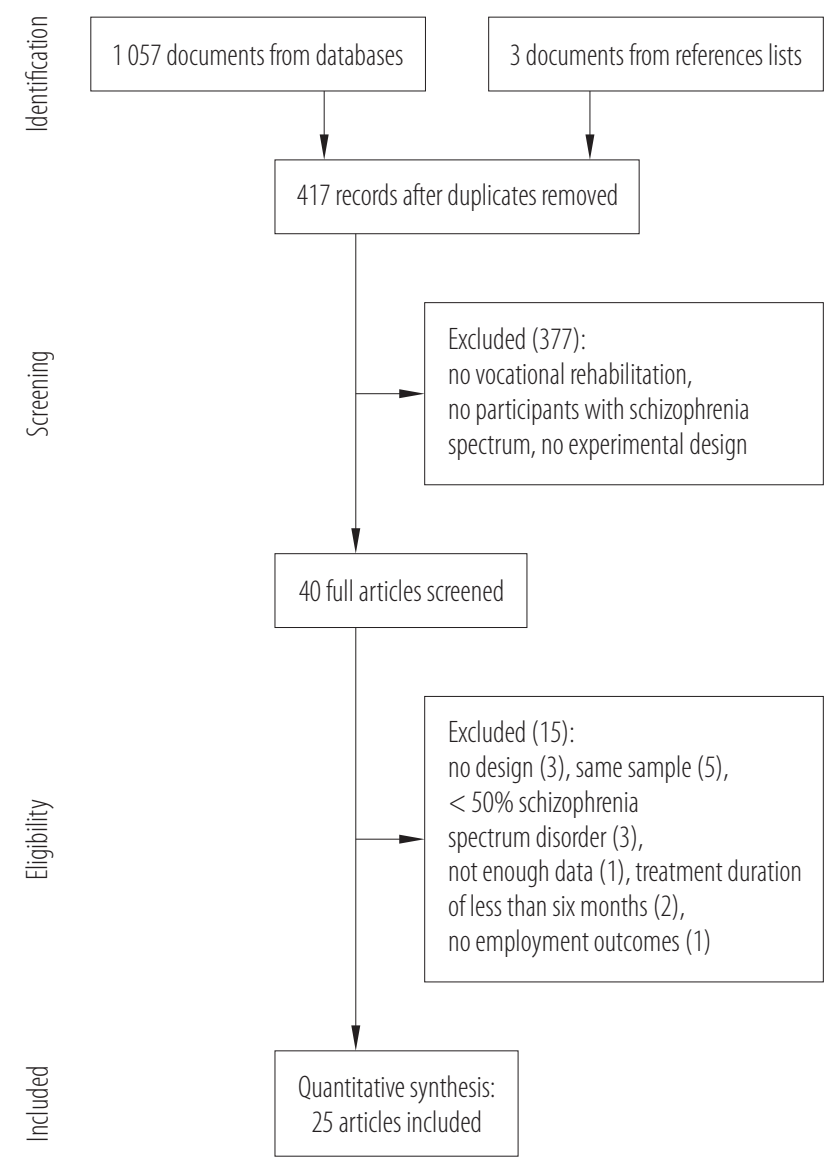

Fig. 1. Selection process for study inclusion in the meta-analysis of the studies on effectiveness of treatments to enhance employment outcomes for people with schizophrenia spectrum disorder standard deviation $(\mathrm{SD})=6.81$ ). Methodological quality scores ranged from 7 to 16 (mean $=11.88 ; \mathrm{SD}=2$ ). The mean age of subjects was 37.69 years old (range: $24.5-$ 51.03 ; SD $=6.61), 62.51 \%$ were men and $47.52 \%$ were from a non-Caucasian population.

The sample comprised 866 people with schizophrenia, 299 with schizoaffective disorder and 1199 with schizophrenia spectrum diagnosis; this last category corresponded to 12 studies that included samples of patients with schizophrenia, schizoaffective disorder and other psychotic disorders but did not report exact numbers. All subjects were under antipsychotic treatment. Nineteen studies reported work status which included the categories "unemployed" and "substantially underemployed." Sixteen trials reported on participants interested in getting work. Out of the 8 studies that reported educational level in years, the mean value was 12.5 (range: 11.9-12.7, $\mathrm{SD}=0.27$ ). Data for illness duration was only obtained from 12 studies. The average illness duration was 15.37 years (range: $3.19-24.2, \mathrm{SD}=5.73$ ) (see Table 1$)$.

\section{Intervention and control}

All studies compared vocational treatments to enhance employment outcomes for people with schizophrenia with other vocational approaches used as standard treatment to help people access employment, provided by the local vocational rehabilitation services. Modalities derived from supported employment approach were the most commonly used for all variables considered. A smaller number of interventions focused on pay and job placement, job-related social skills training, neurocognitive rehabilitation and cognitive-behavioral intervention. Ten out of the 25 studies used combined treatments. The main combinations consisted of paid employment and job placement at medical center, as single interventions or accompanied by other treatments, such as neurocognitive enhancement therapy or cognitive-behavioral interventions. Neurocognitive enhancement therapy was 


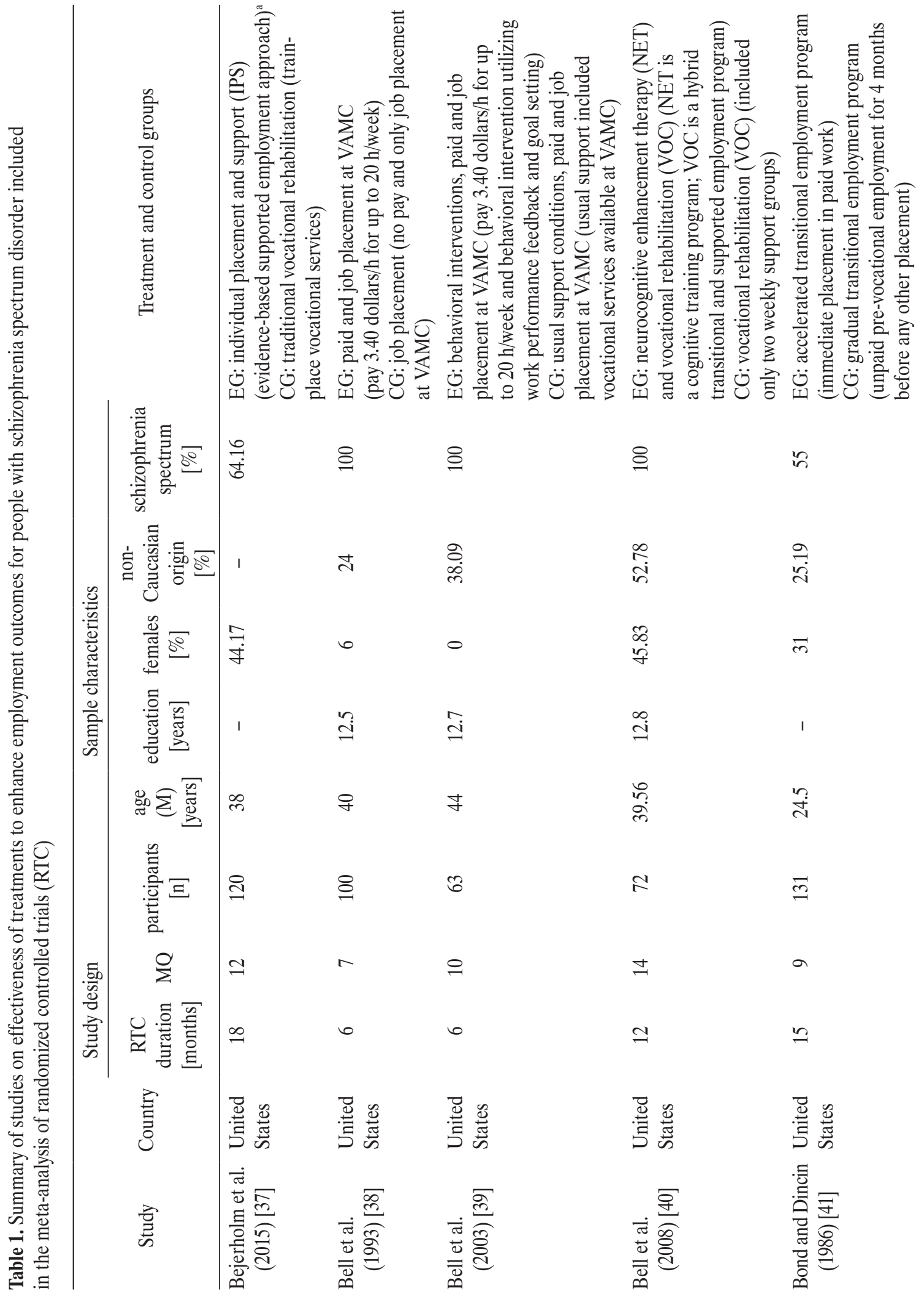




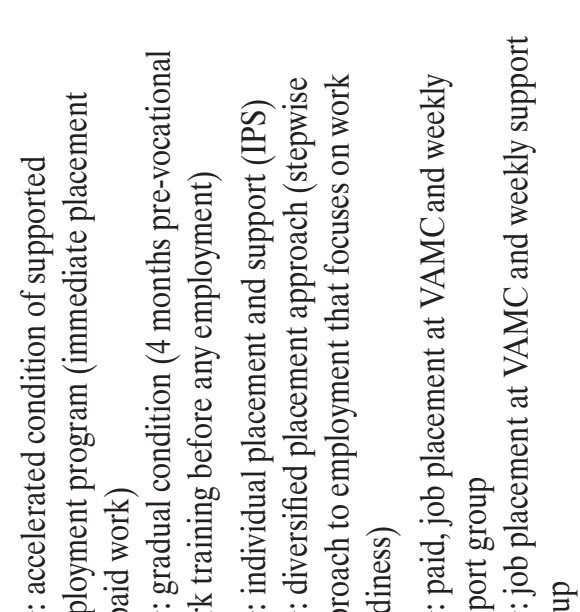

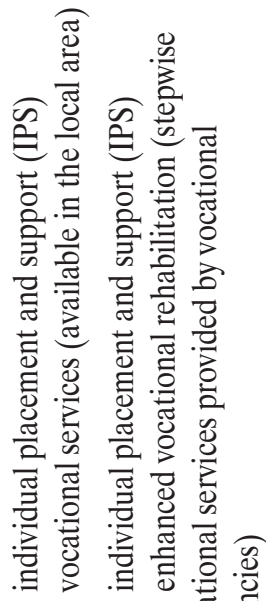

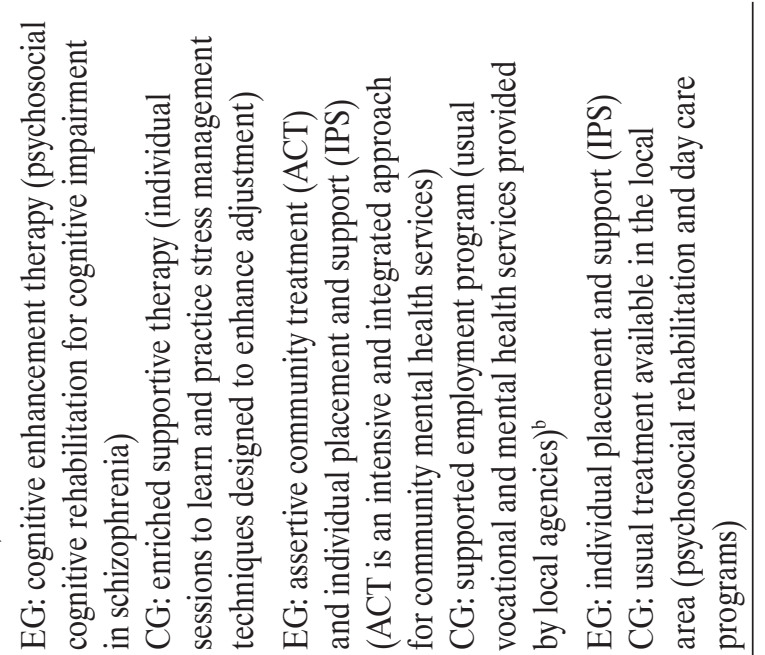

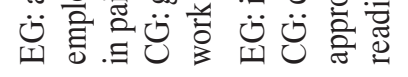

ن言论 论

\begin{tabular}{|c|c|c|c|c|c|c|c|}
\hline 8 & مُ & 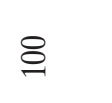 & $\infty$ & 哭 & 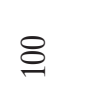 & 吕 & 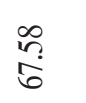 \\
\hline $\overrightarrow{\mathrm{N}}$ & கூ & $\ddot{n}$ & 1 & $\underset{\infty}{\infty}$ & $\stackrel{\overbrace{}}{\stackrel{\infty}{\infty}}$ & $\underset{\infty}{\stackrel{7}{*}}$ & \\
\hline ga & 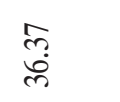 & $\underset{\ngtr}{\Im}$ & q & $\stackrel{\infty}{\overparen{b}}$ & 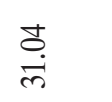 & 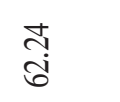 & 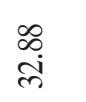 \\
\hline 1 & 1 & $\underset{\mathrm{I}}{\mathrm{U}}$ & $\stackrel{9}{=}$ & 1 & 1 & 1 & । \\
\hline$\frac{3}{m}$ & $\begin{array}{l}2 \\
\stackrel{\infty}{0} \\
\dot{e}\end{array}$ & $\tilde{m}$ & $\underset{\infty}{\stackrel{\infty}{\infty}}$ & ळे. & $\begin{array}{l}\text { ऽे } \\
\text { పे }\end{array}$ & 1 & $\begin{array}{l}\ddot{m} \\
\infty \\
\infty \\
m\end{array}$ \\
\hline ஃ & $\stackrel{\infty}{\infty}$ & sa & $\approx$ & $\stackrel{\sim}{\Omega}$ & $i$ & $\stackrel{\mathscr{g}}{+}$ & $\vec{\sim}$ \\
\hline 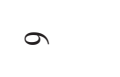 & 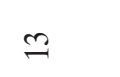 & $\simeq$ & $\simeq$ & $=$ & 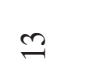 & $m$ & $\simeq$ \\
\hline$\underline{z}$ & $\underset{\sim}{\Delta}$ & 0 & $\stackrel{\infty}{\sim}$ & $\stackrel{\infty}{=}$ & $\underset{d}{ }$ & $\underset{d}{\Delta}$ & $\simeq$ \\
\hline 崽 & 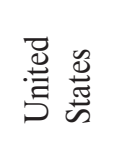 & 总惹 & 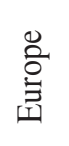 & 总总 & 总总 & 惫总 & 总言 \\
\hline 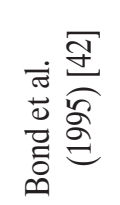 & 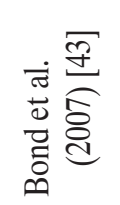 & 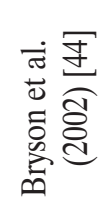 & 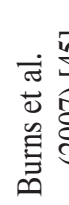 & 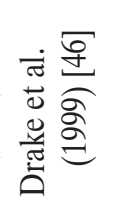 & 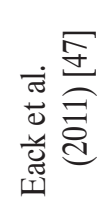 & 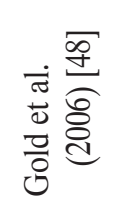 & 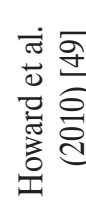 \\
\hline
\end{tabular}




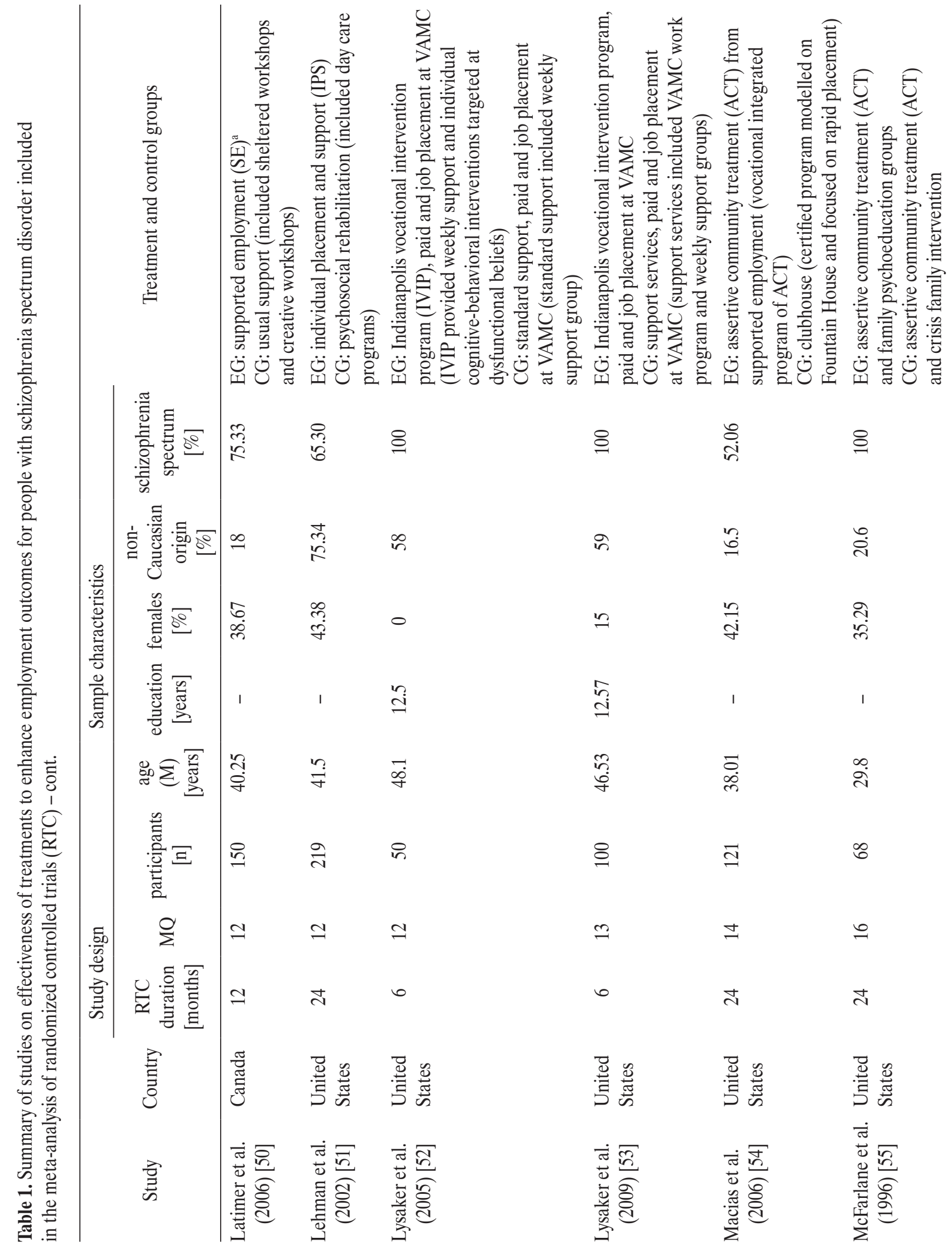



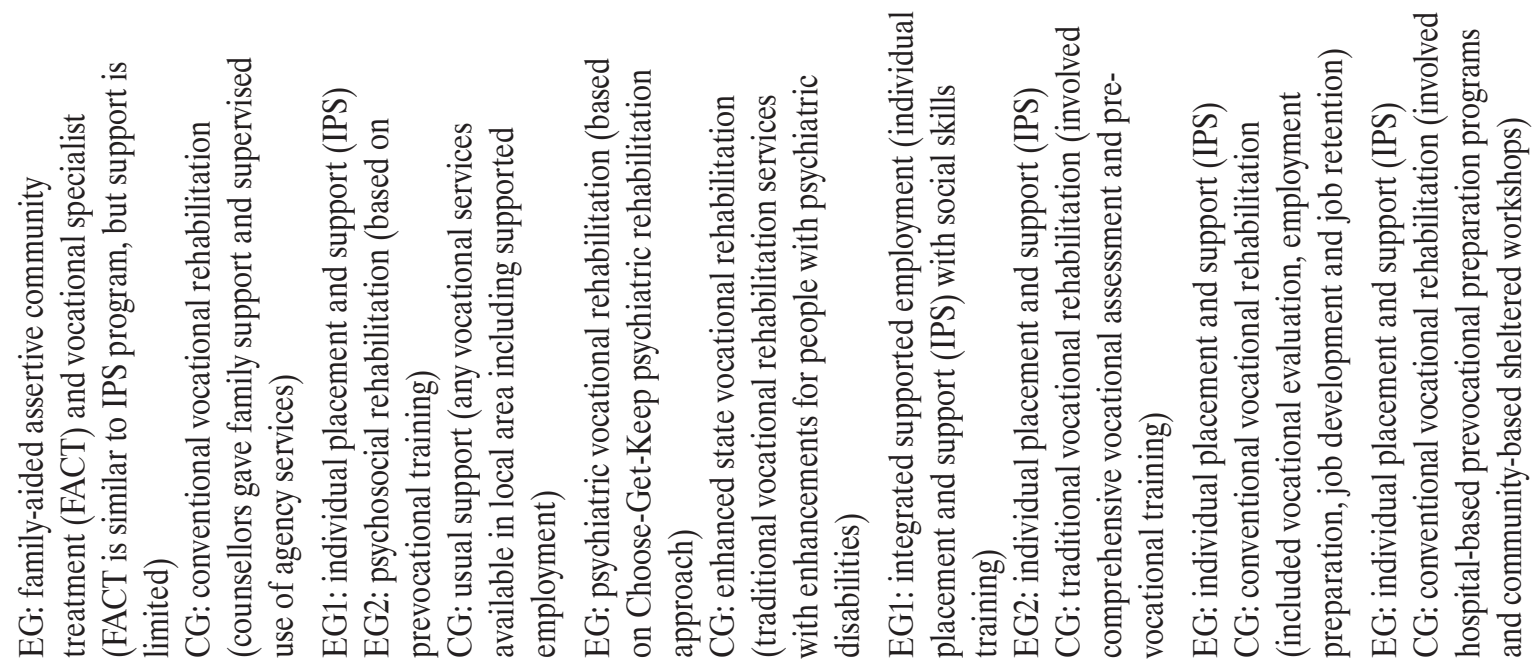

3

ㄱํㅇ

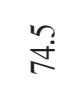

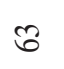

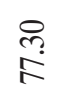

8

fic

守

8

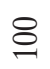

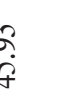

은

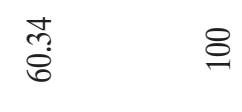

$m$

$\stackrel{\overbrace{}}{ซ}$

के

芦

$\underset{\infty}{\infty}$

m

g)

喜

$\stackrel{n}{2}$

$\underline{6}$

in

$a$

$\stackrel{-}{\sim}$

总总

总营

总颔

节

总兽竞

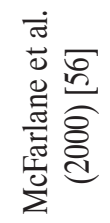

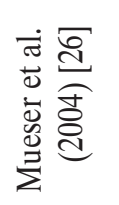

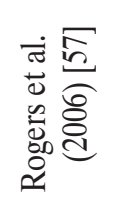

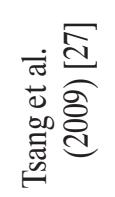
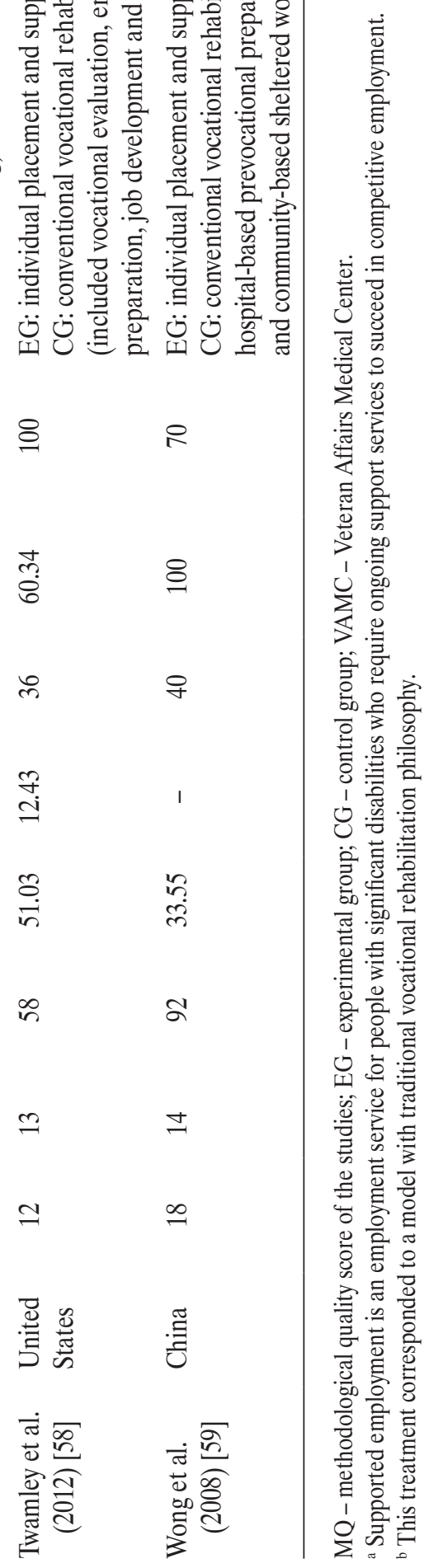
used for addressing cognitive impairments for people with schizophrenia; cognitive-behavioral interventions were targeted to address dysfunctional beliefs and to assess their influence on experiences and work. Two studies compared three approaches to vocational rehabilitation [26,27]. The study by Mueser et al. [26] used individual placement and support, psychosocial rehabilitation and standard services including supported employment; the study by Tsang et al. [27] used integrated supported employment defined as an individual placement and support augmented with social skills training, individual placement and support alone, and traditional vocational rehabilitation, which included pre-vocational training. Twelve studies characterized the treatment similar to "train then place" as the main control group. This treatment involved pre-vocational training (work skills, job search skills or social skills) and volunteer placement or transitional employment before the competitive job. One control group treatment did not focus on employment [47], although it did target the acquisition of skills to cope with job stress. Other control interventions provided a structured system targeting competitive job [48] or paid employment [39].

\section{Job placement}

Competitive job placement

We identified 21 treatments vs. control group comparisons for competitive job placement (19 studies), comprising 2687 participants. A statistically significant heterogeneity was found among these trials $\left(\mathrm{I}^{2}=59.89 \%\right.$, 95\% CI: 32.77-87.83, $\left.\mathrm{p}<0.001\right)$. Randomeffects meta-analysis showed a statistically significant difference favorable to experimental treatments compared to other vocational approaches used as control groups $(\mathrm{RR}=2.31,95 \%$ CI: 1.85-2.88, $\mathrm{p}<0.001, \kappa=21)(\mathrm{Ta}-$ ble 2). Fourteen comparisons provided by 13 studies were found in the subgroup of supported employment treatments. The effect sizes were homogeneously distributed
$\left(\mathrm{I}^{2}=0.00 \%, \mathrm{p}=0.06\right)$ and results from a fixed-effects model indicated that participants receiving supported employment-based treatments showed significantly better competitive job placement outcomes than those receiving other vocational treatments $(\mathrm{RR}=2.49,95 \% \mathrm{CI}: 2.16$ 2.88, $\mathrm{p}<0.0001$ ) (Table 3). Another subgroup of seven interventions not based on the supported employment approach (seven studies) showed the lesser but significant difference indicating better outcomes for participants in intervention groups $(\mathrm{RR}=1.41,95 \% \mathrm{CI}$ : $1.10-1.81$, $\mathrm{p}<0.001)$. The effect sizes were also homogeneously distributed $\left(\mathrm{I}^{2}=0.00 \%, \mathrm{p}=0.11\right)$.

\section{Job placement in any job}

We found 12 comparisons from 11 trials that provided data for job placement in any job, involving 1501 participants. The results from the random-effects model showed no significant difference between treatment and control $(\mathrm{RR}=1.25,95 \% \mathrm{CI}: 0.79-2.00, \mathrm{p}=0.33)$ and high heterogeneity in effect sizes $\left(\mathrm{I}^{2}=94.67 \%, 95 \%\right.$ CI: $88.63-$ $98.29, \mathrm{p}<0.001)$. Similarly, no significant difference was observed between supported employment and other vocational treatments across eight comparisons (from eight trials $)(\mathrm{RR}=1.33,95 \% \mathrm{CI}: 0.69-2.57, \mathrm{p}=0.39)$. Finally, four comparisons of non-supported employment interventions (from three studies) reported no significant differences between treatment and control $(\mathrm{RR}=1.09,95 \% \mathrm{CI}$ : 0.61 $1.94, \mathrm{p}=0.76)$.

\section{Job tenure}

\section{Competitive job tenure}

Ten comparisons for job tenure measured as hours worked (from nine trials) and 11 comparisons for job tenure assessed as weeks worked (nine studies) were identified. Both analyses involved 1962 participants. Trials targeting competitive job tenure did not report a significant difference between treatment and control in terms of hours worked $(\mathrm{SMD}=0.88,95 \% \mathrm{CI}:-0.25-2.01, \mathrm{p}=0.12)$ or weeks 
Table 2. Competitive job placement in the studies on effectiveness of treatments to enhance employment outcomes for people with schizophrenia spectrum disorder

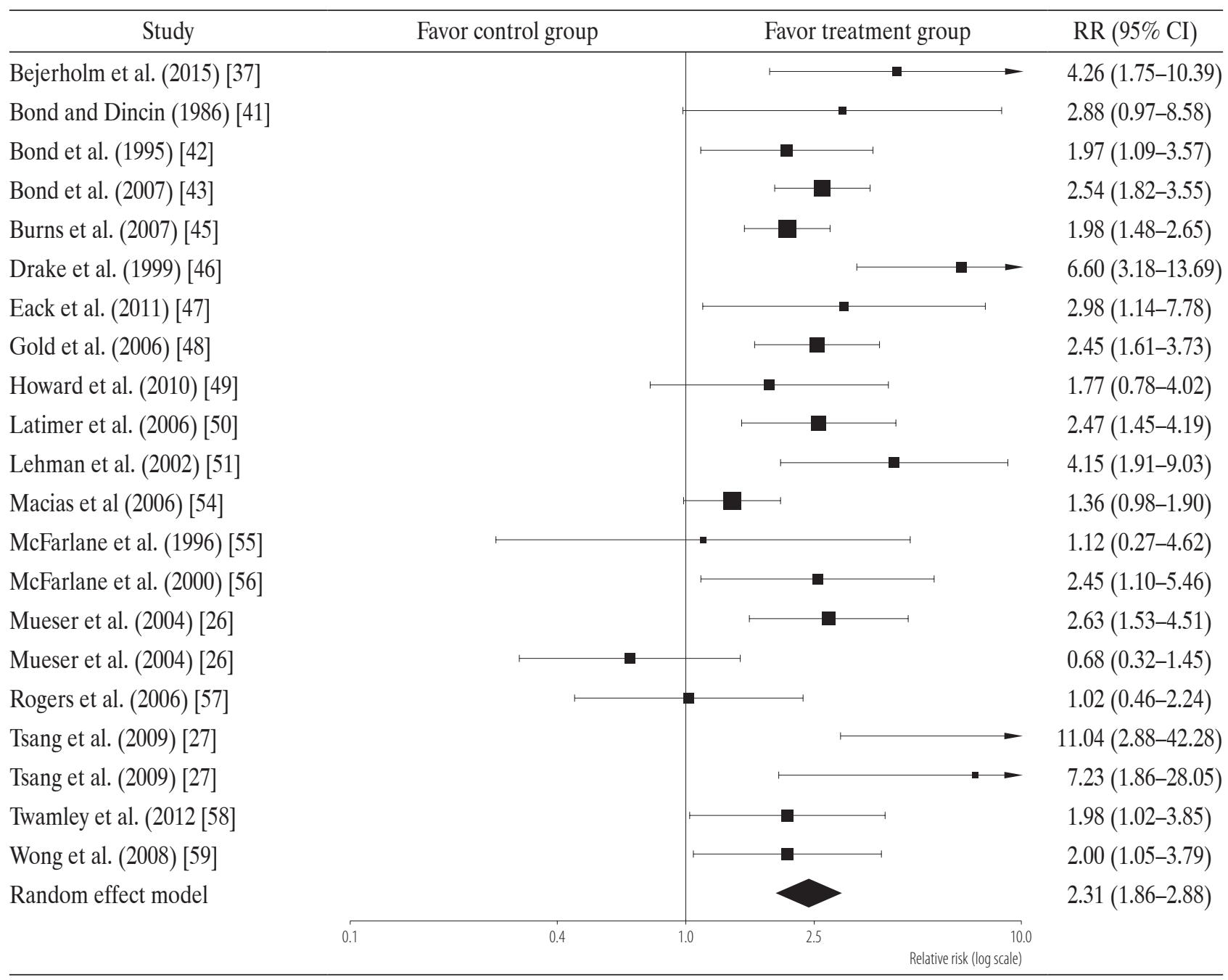

Risk ratio (RR) values greater than 1 indicate better treatment efficacy in the intervention group relative to the control groups. The arrow to the right of the confidence interval $(\mathrm{CI})$ indicates that the value exceeds the limit set for the effect size axis and is therefore situated further to the right. The area of the squares is proportional to the contribution of each study to the global outcome.

worked (SMD $=1.19,95 \%$ CI: $-0.06-2.45, \mathrm{p}=0.06)$. In the subgroup of supported employment treatments, no significant difference was seen between participants receiving supported employment and those taking part in other interventions across seven comparisons that reported competitive hours worked (seven trials) (SMD $=1.31,95 \%$ CI: -0.24 $2.86, \mathrm{p}=0.09$ ). The same result was obtained for 10 comparisons of supported employment (nine studies) that reported competitive weeks worked (SMD $=1.33,95 \%$ CI: $-0.02-$ $2.69, \mathrm{p}=0.06)$. Another subgroup of three comparisons (three studies) that incorporated treatments not based on supported employment and measured competitive hours worked did not produce statistically significant results (SMD $=-0.09,95 \%$ CI: $-0.33-0.13, p=0.41)$. Only one comparison in this subgroup was obtained for competitive weeks worked and the intervention was not found to have 
Table 3. Competitive job placement from supported employment interventions in the studies on effectiveness of treatments to enhance employment outcomes for people with schizophrenia spectrum disorder

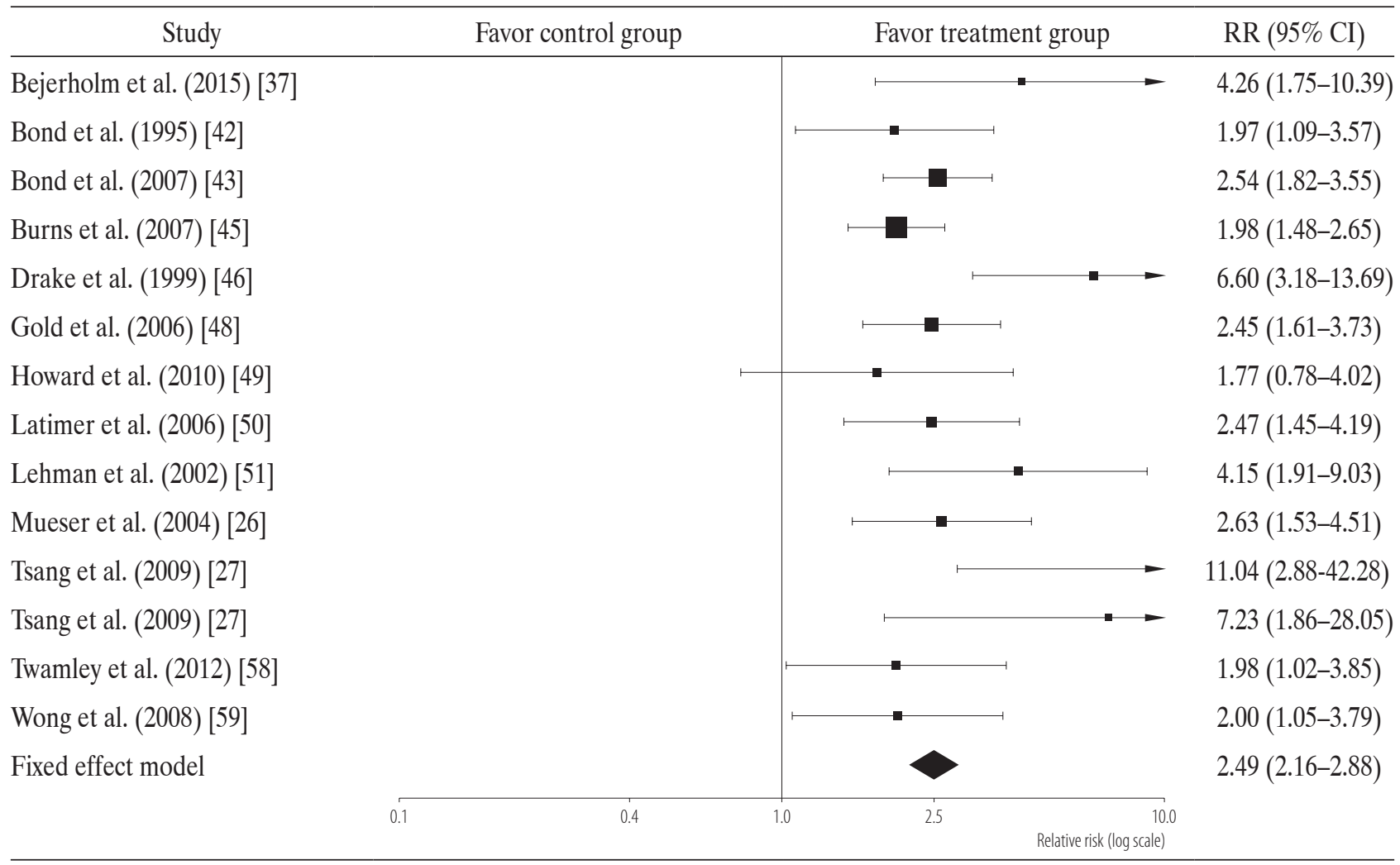

Explanations as in Table 2.

a significant effect $(\mathrm{SMD}=-0.16,95 \% \mathrm{CI}:-0.57-0.25$, $\mathrm{p}=0.44$ ).

\section{Job tenure in any job}

We identified 13 comparisons (12 studies) of job tenure in any job measured as hours worked and five comparisons (four trials) of job tenure in any job assessed as weeks worked. Both analyses comprised 1527 participants. A significant and high heterogeneity in effect sizes was found for hours worked in any job $\left(\mathrm{I}^{2}=82.79 \%, 95 \%\right.$ CI: 65.88 93.80, $\mathrm{p}<0.001)$. The random-effects model showed a small but significant difference for this outcome [60] favorable to participants in intervention groups $(\mathrm{SMD}=0.42,95 \%$ CI: 0.16-0.68, $\mathrm{p}=0.001)$ (Table 4). No significant difference was observed between treatment and control in five comparisons assessing weeks worked in any job (SMD $=0.34,95 \%$ CI: $-0.06-0.74, \mathrm{p}=0.10$ ).

Among six comparisons (six trials) derived from a subgroup of supported employment interventions, participants receiving supported employment treatments worked more hours than those receiving other treatments (SMD $=0.38,95 \%$ CI: 0.03-0.73, $\mathrm{p}=0.03$ ); however, high heterogeneity among effect sizes was found $\left(\mathrm{I}^{2}=84.30 \%, 95 \%\right.$ CI: 59.05-97.48, $\mathrm{p} \leq$ 0.001) (Table 5). Seven comparisons of hours worked in any job were identified in a subset of seven studies with treatments not based on supported employment. The results revealed high heterogeneity in effect sizes $\left(\mathrm{I}^{2}=82.50 \%, 95 \%\right.$ CI: 57.70 96.32, $\mathrm{p}<0.001$ ), and random-effects meta-analysis showed significantly better outcomes among participants 
Table 4. Job tenure in any job measured as hours worked in the studies on effectiveness of treatments to enhance employment outcomes for people with schizophrenia spectrum disorder

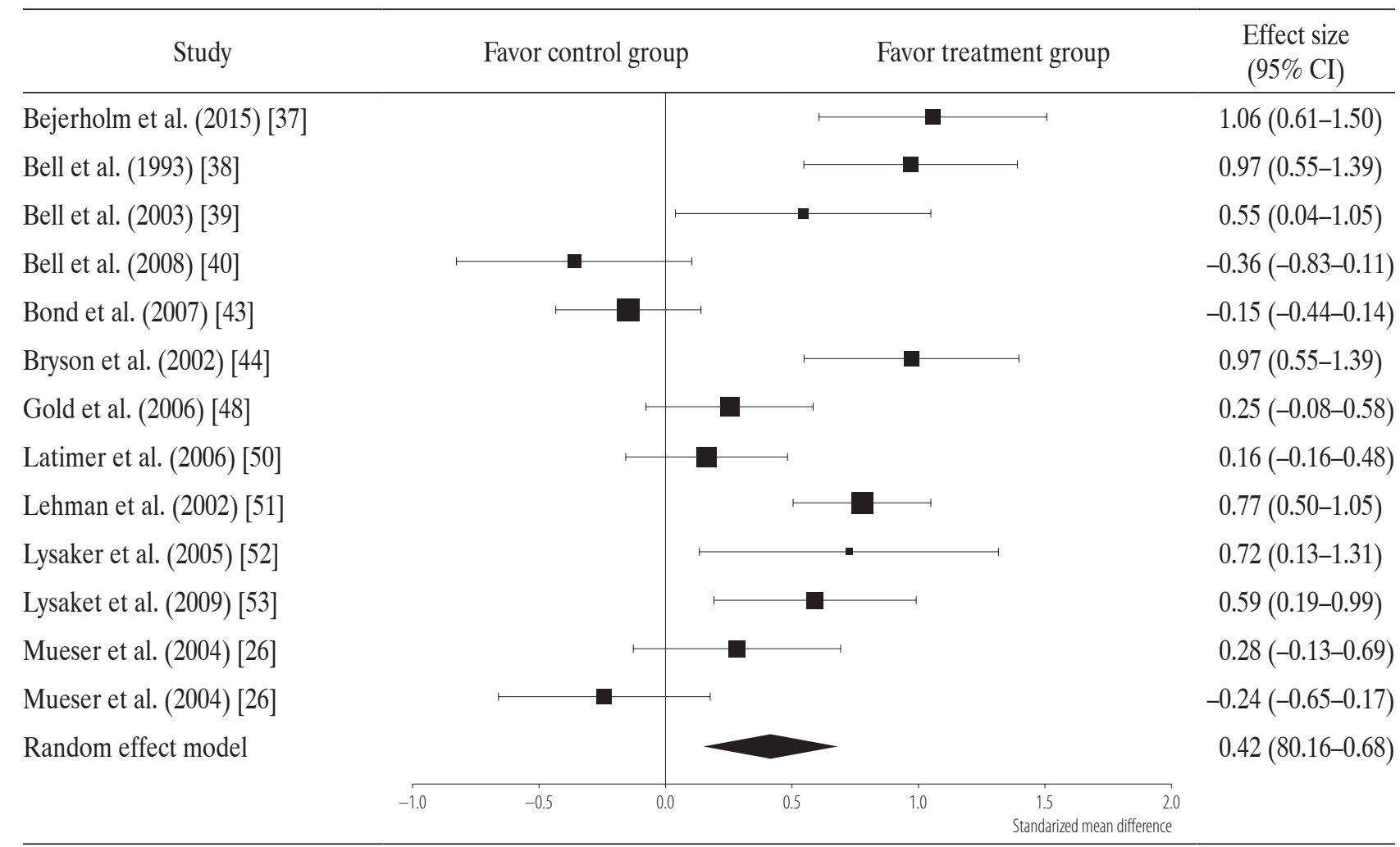

CI - confidence interval.

Standardized mean difference values greater than 0 indicate better treatment efficacy in the intervention group relative to the control group.

The area of the squares is proportional to the contribution of each study to the global outcome.

Table 5. Job tenure in any job measured as hours worked from supported employment interventions in the studies on effectiveness of treatments to enhance employment outcomes for people with schizophrenia spectrum disorder

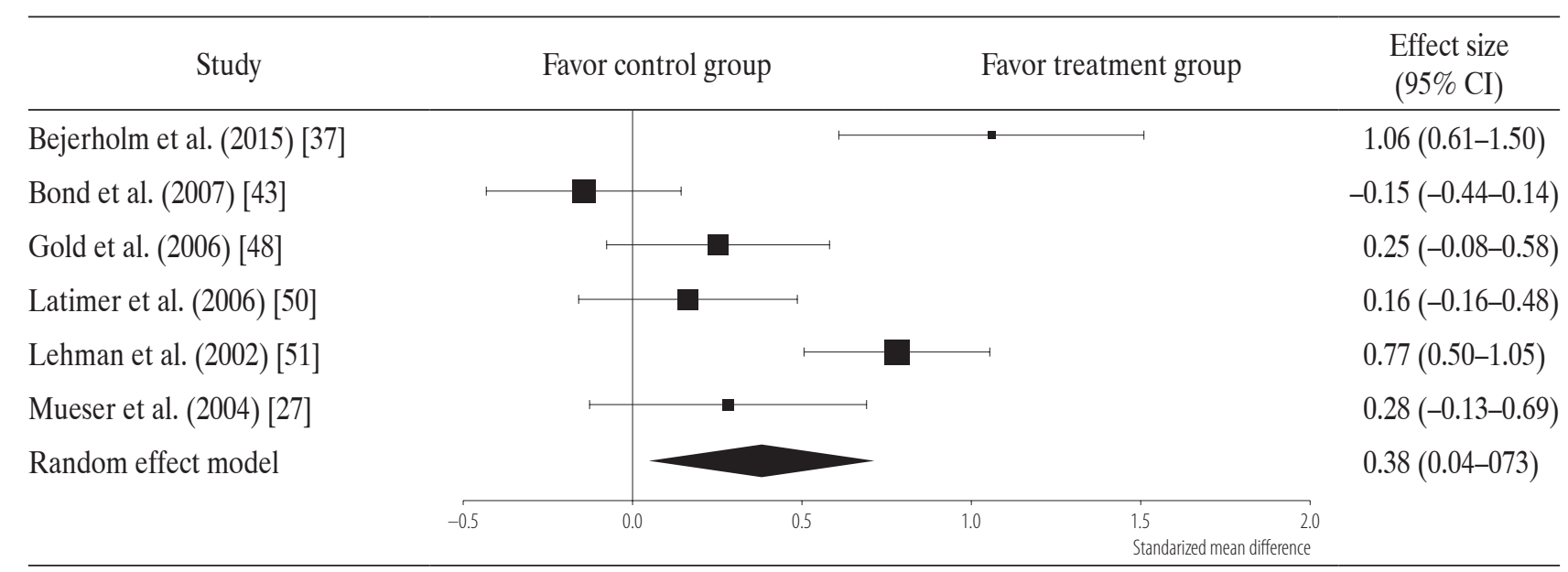

Explanations as in Table 4. 
in intervention groups (SMD $=0.45,95 \%$ CI: 0.04-0.86, $\mathrm{p}=0.02$ ). A subgroup analysis of supported employment interventions for weeks worked in any job was not carried out because these studies corresponded to the same set of trials previously analyzed in the overall analysis. We did not identify studies reporting data on weeks worked from interventions not based on supported employment.

\section{Wages earned}

Ten studies that provided 11 treatments versus control comparisons were identified. We did not find a significant difference between treatment and control in the overall analysis (SMD $=0.84,95 \%$ CI: $-0.16-1.85, \mathrm{p}=0.10$ ), in a subgroup analysis of seven comparisons for supported employment (seven trials) (SMD $=1.25,95 \%$ CI: -0.29 $2.80, \mathrm{p}=0.11$ ), or in a subgroup analysis of four comparisons (four studies) for interventions not based on supported employment $(\mathrm{SMD}=0.12,95 \% \mathrm{CI}:-0.27-0.51$, $\mathrm{p}=0.54)$.

\section{Publication bias}

We found evidence suggestive of publication bias for competitive job placement in the subgroup analysis of 14 supported employment interventions $($ Egger $=2.82, \mathrm{p}=0.015)$. There was no evidence of publication bias in the remaining significant variables of this study.

\section{Sensitivity analysis}

The sensitivity analysis did not significantly alter the outcomes for competitive job placement. No significant treatment effect on hours worked in any job was observed when combined treatments and studies in which employment outcome was a secondary goal were omitted. A sensitivity analysis of the subgroup of supported employment interventions showed no significant changes in competitive job placement outcomes. Due to the small number of studies, sensitivity analysis for hours worked in any job was not carried out in the subgroup of supported employment interventions or the subgroup of interventions not based on supported employment. Similarly, sensitivity analysis for competitive employment was not conducted in the subgroup of non-supported employment interventions (see Table 6).

\section{Moderator effects on employment}

In the overall analysis, the study and sample characteristics had no moderator effects on competitive job placement. For hours worked in any job, the meta-regression model containing quality scores as predictors and effect sizes as dependent variables was significant $(\beta=-0.157$, $\mathrm{p}=0.01$ ), indicating that lower quality was associated with larger effect sizes. The residual heterogeneity was high $\left(\mathrm{I}^{2}=76.25 \%, 95 \%\right.$ CI: 51.57-91.99). In the subgroup of supported employment interventions and the subgroup of non-supported employment interventions, sensitivity analysis for hours worked in any job was not conducted due to the insufficient number of trials.

\section{DISCUSSION}

This study provides a quantitative synthesis of 25 interventions that have been used to enhance the employment outcomes of people with schizophrenia. Overall, intervention had an effect on competitive job placement and job tenure in any job (measured as hours worked). Participants from treatments corresponding to experimental groups increased their likelihood of obtaining a competitive job during the course of the studies ( $\mathrm{RR}=2.31,95 \% \mathrm{CI}$ : $1.85-$ 2.88, $\kappa=21, \mathrm{p}<0.001)$. Intervention also had a small effect [60] on job tenure assessed as hours worked in any job (SMD $=0.42,95 \%$ CI: $0.16-0.68, \kappa=13, p=0.001$ ). Analysis of heterogeneity within competitive job placement did not reveal an association with the collected variables. The large heterogeneity for hours worked in any job was mainly accounted for by the quality score of the studies. Intervention targeting hours worked in any job was more likely to be effective in studies of lower 


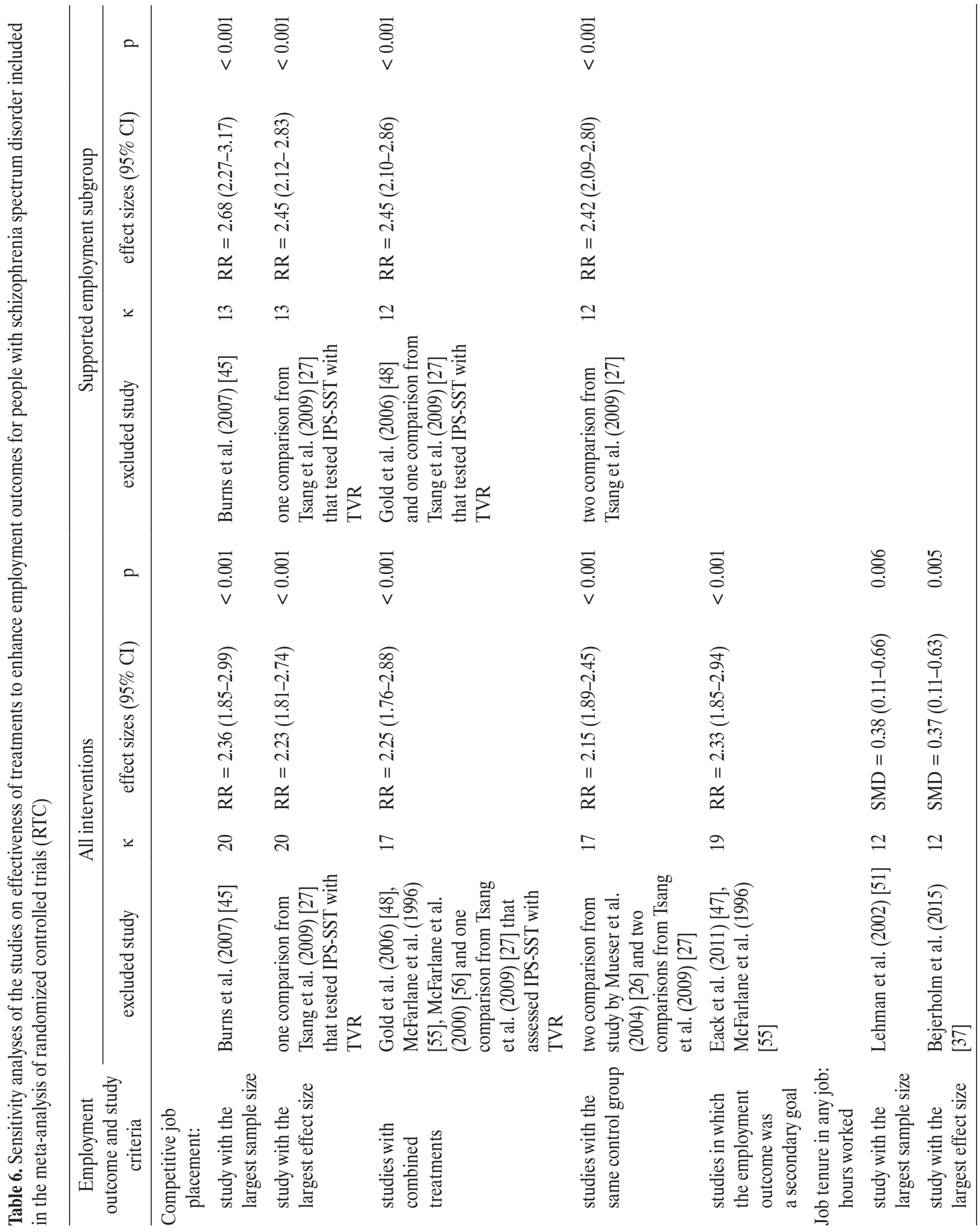




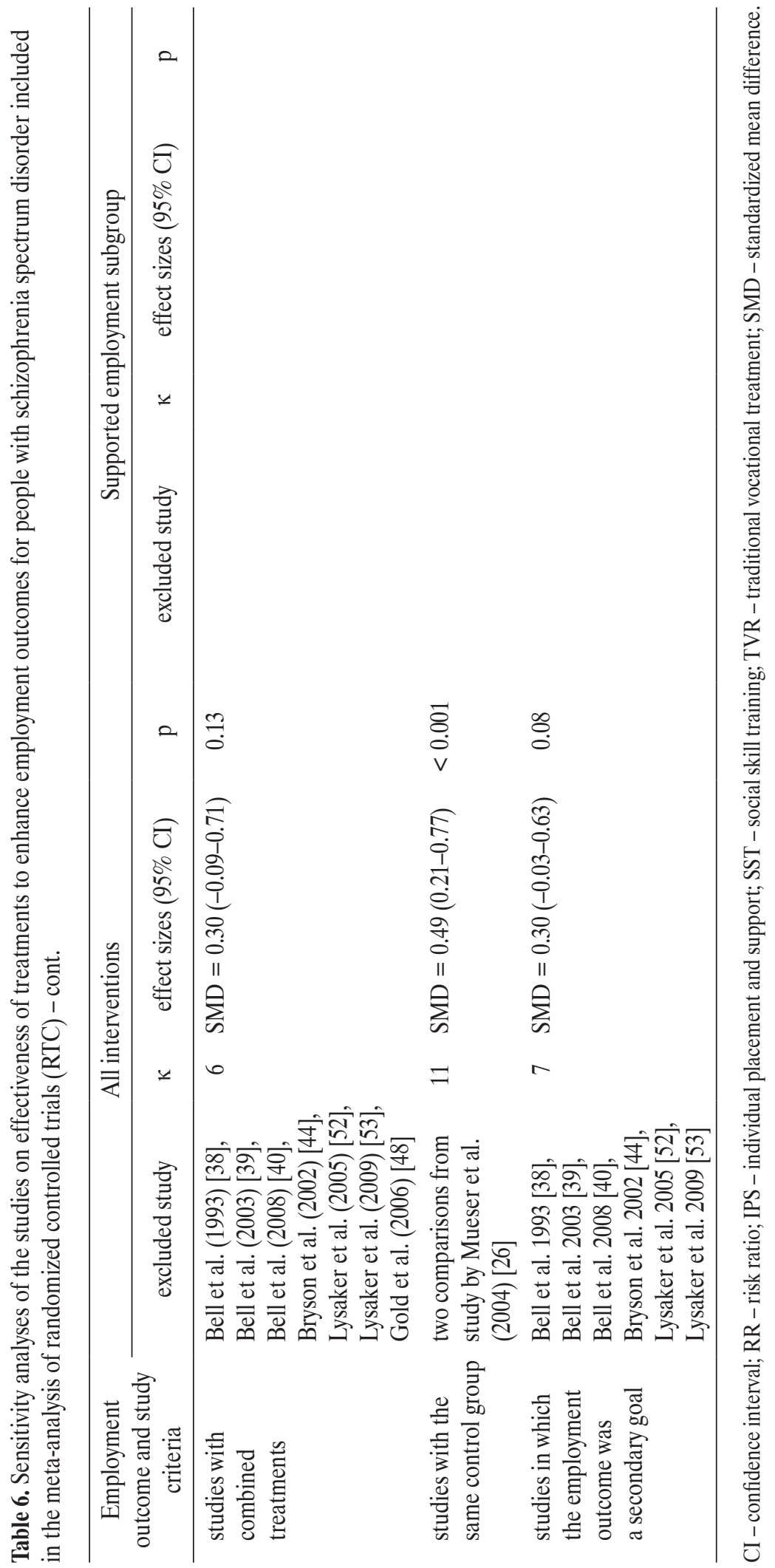


methodological quality, illustrating that the quality with which employment programs are implemented is particularly relevant in trials designed to assess the effectiveness of these programs.

Similarly to the overall analysis, in the subgroups of trials that applied vocational treatments based on the supported employment approach and treatments not based on supported employment, competitive job placement and tenure in any job (measured as hours worked) were significant. The effect of the supported employment interventions on competitive job placement was greater than the effect obtained from the overall analysis and the effect obtained for the subgroup of studies that used non-supported employment treatments, a pattern that confirms a previous report in the literature for people with schizophrenia [16] and severe mental illness [11,13]. By contrast, the effect of supported employment-based interventions on hours worked in any job was less than the effect obtained from the overall analysis and the effect obtained for subgroup of studies that used non-supported employment treatments. We believe that this difference may be due to the nature of the supported employment approach, which specifically targets competitive employment, and to the small number of studies considered in these analyses. Treatment was not found to have an effect on job placement in any job, competitive job tenure (measured as hours or weeks), job tenure in any job (measured as weeks worked) or competitive wages earned. It is possible that the consideration of short periods as indicative of job placement success could overestimate the employment rate. For example, Macias et al. [54] defined job acquisition as successful if the participants worked "at least five days;" Burns et al. [45] and Howard et al. [49] defined a period of "at least one day." Therefore, the competitive job tenure and wages earned would reflect the sum of hours or weeks worked by many individuals, each of whom only worked for a short period of time. Similarly, although there is consensus about the importance of remaining in employment to increase opportunities for involvement in the community and for economic self-sufficiency, early onset of schizophrenia may hinder educational achievement, work experience or the development of life skills necessary for work [61].

The general labor market conditions of each country or region, such as employment rates in the general population, access to welfare benefits and availability of vocational services, may also influence employment opportunities and outcomes for people with disabilities [62]. For example, the study by Latimer et al. [50] reported that the advantages of sheltered employment, such as free public transportation or the large number of alternative vocational programs, seemed to have reduced the relative attractiveness of competitive employment for participants. Uncertainty about continued employment and continuity of the care received through vocational services, mainly in interventions configured as a controlled trial with a scheduled end, may also reduce motivation and lead to job abandonment.

For job placement in any job, we believe that the nature of treatments and the aim of trials could have influenced this result, since the majority of the studies were supported employment-based interventions targeting competitive employment, so non-competitive job acquisition was a secondary objective. Although interest in obtaining a job was not significant as a moderator variable in any analysis, participants were mostly recruited for their interest in competitive employment; therefore, their expectations did not correspond to non-competitive job acquisition. Moreover, there were differences in the methods used for addressing this interest among trials. For examples, Drake et al. [46] and Howard et al. [49] recruited people interested in work and assessed eligibility through introductory meetings, whereas Macias et al. [54], due to the nature of their intervention model, did not screen for work interest. The study by Howard et al. [49], which included a single introductory session, is likely to have recruited less motivated 
patients, who would have been excluded from the study by Drake et al. [46]. The availability of employment services and the benefit systems could also affect job placement, especially for people with prolonged illness, the long-term unemployed, and those who choose to work non-competitively. Finally, in term of weeks worked in any job, we believe the small number of studies considered here and the high heterogeneity of effect sizes did not allow the effects of the intervention to be detected.

The sensitivity analysis did not significantly alter outcomes in competitive job placement. However, in the overall analysis there was no evidence of intervention efficacy for hours worked in any job, when studies with combined treatments and studies in which employment was a secondary goal were omitted (see Table 6). Coincidentally, most of the studies omitted were trials that applied programs to enhance cognitive deficits [40] and dysfunctional beliefs [39,52,53] or approaches that used pay as an incentive [39] and provided weekly support group [44]. This result provides valuable information about the relevance in vocational rehabilitation of the improvement of cognitive functions [6] and interventions that provide support groups and encourage participants to reflect on their status as workers and their relationship with employment.

Some limitations should be considered when interpreting our findings. We included studies conducted mainly in the United States, some European countries and trials with samples of at least $50 \%$ of people with schizophrenia, because studies that address only people with schizophrenia are very limited. In terms of methodological quality, we worked only with summation across items of scale and did not conduct item-level statistical analysis to identify which methodological characteristics were most closely related to outcome. Moreover, quality assessment was based on available information for each published report. Additionally, underreporting of potential valuable information regarding people and study characteristics (e.g., years of work experience, type of employment in which people were employed, and socioeconomic status) hindered the analysis of other possible sources of heterogeneity, mainly in overall analysis for competitive job placement, which could not be explained on the basis of the design or the sample features. The analysis of some of the potential moderators was also limited due to a small number of studies. We also found evidence suggestive of bias through Egger's procedure for one significant variable. This suggests that additional studies are necessary to normalize the distribution of effect sizes for this variable; as such, publication bias may be present in this outcome.

Future research should go beyond overcoming these limitations and must focus on people who want to work and their specific employment needs. Furthermore, different socio-economic and cultural contexts need to be considered in order to learn how these particular environments influence the value afforded to work and productivity. Inquiring into participants' beliefs and opinions about employment, to gauge whether their notions of success coincide with the definition proposed in the specific vocational rehabilitation treatments, and the views of their caregivers and relatives is also very important to improving intervention design. Another important aspect to address is the view of some health professionals regarding the negative impact of job stress on people with severe mental disorders, which has a bearing on referrals to vocational services and references for competitive job positions. The scenario requires health professionals to be better equipped to deal with vocational issues, acknowledging job stress as a fact of life that must be accepted and managed with their help, rather than considering it a threat against which people with severe mental disorders must be protected [63]. In addition, both people with schizophrenia and their families and caregivers must remember that relapse is a possibility in the course of the illness. Therefore, better preparation and close accompaniment for coping with risk factors such as job stress might be useful 
in enabling people with schizophrenia to remain and make progress in their jobs.

Crucially, more studies are needed to assess the influence of other demographic variables (e.g., the patients' desire to work and their neurocognitive functioning) and features of the labor market (e.g., salary, unemployment rates and benefits) on treatment outcomes. Studies with a longer follow-up should be conducted to discern the durability of the effect, the influence of work activity on symptomatic stability, and the subsequent incidence of relapses. Without substantial follow-up periods, we can learn little about how people with schizophrenia fit into the workplace and develop their careers.

\section{CONCLUSIONS}

Our findings suggest that, given the tremendous impact of schizophrenia on several areas of daily functioning, participation in rehabilitation treatment targeting employment outcomes is not sufficient to ensure labor stability. A comprehensive approach that considers dynamic interaction between unemployment rates, personal characteristics and vocational rehabilitation outcomes, and a coordinated effort between health services, employment services and social services, are imperative to address unemployment. Similar to previous findings $[15,16]$, the supported employment approach combined with interventions targeting the significant deficits associated with schizophrenia, such us neurocognitive therapy and job related social skill training, appears to hold the key to successfully addressing the multicausality of work disability, since these interventions would be applicable to a greater number of cases and compatible with a wider range of employment outcomes in schizophrenia.

\section{REFERENCES}

1. Chow CM, Cichocki B. Predictors of job accommodations for individuals with psychiatric disabilities. Rehabil Couns Bull. 2015;1-13:72, https://doi.org/10.1177/0034355215583057.
2. Rosenheck R, Leslie D, Keefe R, McEvoy J, Swartz M, Perkins $\mathrm{D}$, et al. Barriers to employment for people with schizophrenia. Am J Psychiatry. 2006;163(3):411-7, https://doi. org/10.1176/appi.ajp.163.3.411.

3. Salkever DS, Karakus MC, Slade EP, Harding CM, Hough RL, Rosenheck RA, et al. Measures and predictors of community-based employment and earnings of persons with schizophrenia in a multisite study. Psychiatr Serv. 2007;58:315-24, https://doi.org/10.1176/ps.2007.58.3.315.

4. Marwaha S, Johnson S, Bebbington P, Stafford M, Angermeyer MC, Brugha T, et al. Rates and correlates of employment in people with schizophrenia in the UK, France and Germany. Br J Psychiatry. 2007;191:30-7, https://doi. org/10.1192/bjp.bp.105.020982.

5. Killackey E. Something for everyone: Employment interventions in psychotic illness. Acta Neuropsychiatr. 2008;20(5):277-9, https://doi.org/10.1111/j.1601-5215.2008. 00327.x.

6. Charzyńska K, Kucharska K, Mortimer A. Does employment promote the process of recovery from schizophrenia? A review of existing evidence. Int J Occup Med Environ Health. 2015;28(3):407-18, https://doi.org/10.13075/ ijomeh.1896.00341.

7. Kager A, Lang A, Berghofer G, Henkel H, Schmitz M. The impact of work on quality of life for persons with severe mental illness. Nervenheilkunde. 2000;19:560-5.

8. Krupa T. Employment, recovery, and schizophrenia: Integrating health and disorder at work. Psychiatr Rehabil J. 2004;28:8-15, https://doi.org/10.2975/28.2004.8.15.

9. Tandberg M, Ueland T, Andreassen OA, Sundet K, Melle I. Factors associated with occupational and academic status in patients with first-episode psychosis with a particular focus on neurocognition. Soc Psychiatry Psychiatr Epidemiol. 2012;47(11):1763-73, https://doi.org/10.1007/s00127012-0477-x.

10. Campbell K, Bond GR, Drake RE. Who benefits from supported employment: A meta-analytic study. Schizophr Bull. 2011;37(2):370-80, https://doi.org/10.1093/schbul/sbp066. 
11. Kinoshita Y, Furukawa TA, Kinoshita K, Honyashiki M, Omori IM, Marshall M, et al. Supported employment for adults with severe mental illness. Cochrane Database Syst Rev. 2013;13:9, https://doi.org/10.1002/14651858.cd008297. pub2.

12. Marshall T, Goldberg RW, Braude L, Dougherty RH, Daniels AS, Ghose SS, et al. Supported employment: Assessing the evidence. Psychiatr Serv. 2014;65(1):16-23, https://doi. org/10.1176/appi.ps.201300262.

13. Modini M, Tan L, Brinchmann B, Wang M-J, Killackey E, Glozier N, et al. Supported employment for people with severe mental illness: Systematic review and meta-analysis of the international evidence. Br J Psychiatry. 2016;209(1): 14-22, https://doi.org/10.1192/bjp.bp.115.165092.

14. Cook JA, Razzano L. Vocational rehabilitation for persons with schizophrenia: Recent research and implications for practice. Schizophr Bull. 2000;26(1):87-103, https://doi. org/10.1093/oxfordjournals.schbul.a033448.

15. Lim Y, Millington M, Mpofu E. The evidentiary basis for supported employment practice for workers with schizophrenia: A thematic analysis. Am J Psychiatr Rehabil. 2014;17:93-113, https://doi.org/10.1080/15487768.2013. 877409.

16. Twamley EW, Jeste DV, Lehman AF. Vocational rehabilitation in schizophrenia and other psychotic disorders: A literature review and meta-analysis of randomized controlled trials. J Nerv Ment Dis. 2003;191(8):515-23, https://doi. org/10.1097/01.nmd.0000082213.42509.69.

17. Harvey PD, Heaton RK, Carpenter WT, Green MF, Gold JM, Schoenbaum M. Functional impairment in people with schizophrenia: Focus on employability and eligibility for disability compensation. Schizophr Res. 2012;140(1-3):1-8, https://doi.org/10.1016/j.schres.2012.03.025.

18. Moher D, Liberati A, Tetzlaff J, Altman DG; de PRISMA Group. Preferred reporting items for systematic reviews and meta-analyses: The PRISMA Statement. Ann Intern Med. 2009;151(4):264-9, https://doi.org/10.7326/0003-4819-151-4200908180-00135.
19. Bromet EJ, Kotov R, Fochtmann LJ, Carlson GA, Tanenberg-Karant M, Ruggero C, et al. Diagnostic shifts during the decade following first admission for psychosis. Am J Psychiatry. 2011;168(11):1186-94, https://doi.org/10.1176/appi. ajp.2011.11010048.

20. Rinaldi M, Killackey E, Smith J, Shepherd G, Singh SP, Craig T. First episode psychosis and employment: A review. Int Rev Psychiatry. 2010;22(2):148-62, https://doi. org/10.3109/09540261003661825.

21. Cook JA, Leff HS, Blyler CR, Gold PB, Goldberg RW, Mueser KT, et al. Results of a multisite randomized trial of supported employment interventions for individuals with severe mental illness. Arch Gen Psychiatry. 2005;62(5):50512, https://doi.org/10.1001/archpsyc.62.5.505.

22. Miller WR, Brown JM, Simpson TL, Handmaker NS, Bien TH, Luckie LF, et al. What works? A methodological analysis of the alcohol treatment outcome literature. In: Hester RK, Miller WR, editors. Handbook of alcoholism treatment approaches: Effective alternatives. Boston: Allyn and Bacon; 1995. p. 12-44.

23. Jadad AR, Moore RA, Carroll D, Jenkinson C, Reynolds DJ, Gavaghan DJ, et al. Assessing the quality of reports of randomized clinical trials: Is blinding necessary? Control Clin Trials. 1996;17(1):1-12, https://doi.org/10.1016/01972456(95)00134-4.

24. Cohen J. Weighted kappa: Nominal scale agreement provision for scaled disagreement or partial credit. Psychol Bull. 1968;70(4):213-20.

25. Hedges LV. Distribution theory for Glass's estimator of effect size and related estimators. J Educ Behav Stat. 1981; 6(2):107-28, https://doi.org/10.3102/10769986006002107.

26. Mueser KT, Clark RE, Haines M, Drake RE, McHugo GJ, Bond GR, et al. The Hartford study of supported employment for persons with severe mental illness. J Consult Clin Psychol. 2004;72(3):479-90, https://doi.org/10.1037/0022006X.72.3.479.

27. Tsang HW, Chan A, Wong A, Liberman RP. Vocational outcomes of an integrated supported employment program 
for individuals with persistent and severe mental illness. J Behav Ther Exp Psychiatry. 2009;40(2):292-305, https://doi. org/10.1016/j.jbtep.2008.12.007.

28. Higgins JP, Thompson SG. Quantifying heterogeneity in a meta-analysis. Stat Med. 2002;21(11):1539-58, https://doi. org/10.1002/sim.1186.

29. Huedo-Medina TB, Sanchez-Meca J, Marin-Martinez F, Botella J. Assessing heterogeneity in meta-analysis: Q statistic or $\mathrm{I}^{2}$ index? Psychol Methods. 2006;11(2):193-206, https://doi.org/10.1037/1082-989X.11.2.193.

30. Higgins JP, Thompson SG, Deeks JJ, Altman DG. Measuring inconsistency in meta-analyses. BMJ. 2003;327(7414): 557-60, https://doi.org/10.1136/bmj.327.7414.557.

31. Hedges LV, Olkin I. Statistical methods for meta-analysis. Orlando: Academic Press; 1985.

32. Begg CB, Mazumdar M. Operating characteristics of a rank correlation test for publication bias. Biometrics. 1994; 50(4):1088-101, https://doi.org/10.2307/2533446.

33. Egger M, Davey SG, Schneider M, Minder C. Bias in meta-analysis detected by a simple, graphical test. BMJ. 1997;315(7109):629-34, https://doi.org/10.1136/bmj.315.71 09.629 .

34. Sterne JAC, Becker BJ, Egger M. The funnel plot. In: Rothstein HR, Sutton AJ, Borenstein M, editors. Publication bias in meta-analysis: Prevention, assessment and adjustments. Chichester: Wiley; 2005. p. 75-98, https://doi. org/10.1002/0470870168.ch5.

35. Viechtbauer W. Conducting meta-analyses in $\mathrm{R}$ with the metafor package. J Stat Softw. 2010;36(3):1-48, https://doi. org/10.18637/jss.v036.i03.

36. R Core Team [Internet]. Vienna: R Foundation for Statistical Computing; 2014 [cited 2016 May 18]. R: A language and environment for statistical computing [software online]. Version 3.1.2. Available from: http://www.R-project.org.

37. Bejerholm U, Areberg C, Hofgren C, Sandlund M, Rinaldi M. Individual placement and support in Sweden - A randomized controlled trial. Nord J Psychiatry. 2015;69(1):5766, https://doi.org/10.3109/08039488.2014.929739.
38. Bell MD, Milstein RM, Lysaker PH. Pay as incentive in work participation by patients with severe mental illness. Hosp Community Psychiatry. 1993;44(7):684-6, https://doi. org/10.1176/ps.44.7.684.

39. Bell MD, Lysaker PH, Bryson G. A behavioral intervention to improve work performance in schizophrenia: Work behavior inventory feedback. J Vocat Rehabil. 2003;18(1):43-50.

40. Bell MD, Zito W, Greig T, Wexler BE. Neurocognitive enhancement therapy with vocational services: Work outcomes at two-year follow-up. Schizophr Res. 2008;105(1-3):18-29, https://doi.org/10.1016/j.schres.2008.06.026.

41. Bond GR, Dincin J. Accelerating entry into transitional employment in a psychosocial rehabilitation agency. Rehabil Psychol. 1986;31:143-55.

42. Bond GR, Dietzen LL, McGrew JH, Miller LD. Accelerating entry into supported employment for persons with severe psychiatric disabilities. Rehabil Psychol. 1995;40:75-94.

43. Bond GR, Salyers MP, Dincin J, Drake RE, Becker DR, Fraser VV, et al. A randomized controlled trial comparing two vocational models for persons with severe mental illness. J Consult Clin Psychol. 2007;75(6):968-82.

44. Bryson G, Lysaker P, Bell M. Quality of life benefits of paid work activity in schizophrenia. Schizophr Bull. 2002;28(2):249-57,https://doi.org/10.1093/oxfordjournals.sch bul.a006935.

45. Burns T, Catty J, Becker T, Drake RE, Fioritti A, Knapp M, et al. The effectiveness of supported employment for people with severe mental illness: A randomised controlled trial. Lancet. 2007;370:1146-52, https://doi.org/10.1016/S01406736(07)61516-5.

46. Drake RE, McHugo GJ, Bebout RR, Becker DR, Harris M, Bond GR, et al. A randomized control trial of supported employment for inner city patients with severe mental disorder. Arch Gen Psychiatry. 1999;56(7):627-33, https://doi. org/10.1001/archpsyc.56.7.627.

47. Eack SM, Hogarty GE, Greenwald DP, Hogarty SS, Keshavan MS. Effects of cognitive enhancement therapy on employment outcomes in early schizophrenia: Results from 
a 2-year randomized trial. Res Soc Work Pract. 2011;21(1):

32-42, https://doi.org/10.1177/1049731509355812.

48. Gold PB, Meisler N, Santos AB, Carnemolla MA, Williams $\mathrm{OH}$, Keleher J. Randomized trial of supported employment integrated with assertive community treatment for rural adults with severe mental illness. Schizophr Bull. 2006;32(2):378-95, https://doi.org/10.1093/schbul/sbi056.

49. Howard LM, Heslin M, Leese M, McCrone P, Rice C, Jarrett M, et al. Supported employment: Randomised controlled trial. Br J Psychiatry. 2010;196(5):404-11, https://doi. org/10.1192/bjp.bp.108.061465.

50. Latimer EA, Lecomte T, Becker DR, Drake RE, Duclos I, Piat M, et al. Generalisability of the individual placement and support model of supported employment: Results of a Canadian randomised controlled trial. Br J Psychiatry. 2006;189:65-73, https://doi.org/10.1192/bjp.bp.105.012641.

51. Lehman AF, Goldberg R, Dixon LB, McNary S, Postrado L, Hackman A, et al. Improving employment outcomes for persons with severe mental illnesses. Arch Gen Psychiatry. 2002;59(2):165-72, https://doi.org/10.1001/archpsyc.59.2.165.

52. Lysaker P, Bond G, Davis LW, Bryson GJ, Bell MD. Enhanced cognitive-behavioral therapy for vocational rehabilitation in schizophrenia: Effects on hope and work. J Rehabil Res Dev. 2005;42(5):673-82, https://doi.org/10.1682/ JRRD.2004.12.0157.

53. Lysaker PH, Davis LW, Bryson GJ, Bell MD. Effects of cognitive behavioral therapy on work outcomes in vocational rehabilitation for participants with schizophrenia spectrum disorders. Schizophr Res. 2009;107(2-3):186-91, https://doi. org/10.1016/j.schres.2008.10.018.

54. Macias C, Rodican CF, Hargreaves WA, Jones DR, Barreira PJ, Wang Q. Supported employment outcomes of a randomized controlled trial of ACT and clubhouse models. Psychiatr Serv. 2006;57(10):1406-15, https://doi.org/10.1176/ps.2006.57.10.1406.

55. McFarlane WR, Dushay RA, Stastny P, Deakins SM, Link B. A comparison of two levels of family-aided assertive community treatment. Psychiatr Serv. 1996;47(7):744-50, https://doi.org/10.1176/ps.47.7.744.

56. McFarlane WR, Dushay RA, Deakins SM, Stastny P, Lukens EP, Toran J, et al. Employment outcomes in family-aided assertive community treatment. Am J Orthopsychiatry. 2000;70(2):203-14.

57. Rogers ES, Anthony WA, Lyass A, Penk WE. A Randomized clinical trial of vocational rehabilitation for people with psychiatric disabilities. Rehabil Couns Bull. 2006;49(143): 143-56, https://doi.org/10.1177/00343552060490030201.

58. Twamley EW, Vella L, Burton CZ, Becker DR, Bell MD, Jeste DV. The efficacy of supported employment for middle-aged and older people with schizophrenia. Schizophr Res. 2012;135(1-3):100-4, https://doi.org/10.1016/j.schres. 2011.11.036.

59. Wong K, Chiu R, Tang B, Mak D, Liu J, Chiu SN. A randomized controlled trial of a supported employment program for persons with long-term mental illness in Hong Kong. Psychiatr Serv. 2008;59(1):84-90, https://doi.org/10.1176/ps. 2008.59.1.84.

60. Cohen J. A power primer. Psychol Bull. 1992;112:155-9, https://doi.org/10.1037/0033-2909.112.1.155.

61. Jonikas JA, Laris A, Cook J. The passage to adulthood: Psychiatric rehabilitation service and transition-related needs of young adult women with emotional and psychiatric disorders. Psychiatr Rehabil J. 2003;27(2):114-21, https://doi. org $/ 10.2975 / 27.2003 .114 .121$.

62. Bouwmans C, de Sonneville C, Mulder CL, Hakkaart-van Roijen L. Employment and the associated impact on quality of life in people diagnosed with schizophrenia. Neuropsychiatr Dis Treat. 2015;11:2125-42, https://doi.org/10.2147/NDT.S83546.

63. Saavedra J, López M, Gonzales S, Cubero R. Does employment promote recovery? Meanings from work experience in people diagnosed with serious mental illness. Cult Med Psychiatry. 2016;40:507-32, https://doi.org/10.1007//11013015-9481-4.

This work is available in Open Access model and licensed under a Creative Commons Attribution-NonCommercial 3.0 Poland License - http://creativecommons.org/ licenses/by-nc/3.0/pl/deed.en. 